\title{
Notched plates in mixed mode loading (I+II): a review based on the local strain energy density and the cohesive zone model
}

\author{
F. Berto ${ }^{a^{*}}$ and J. Gomez
}

${ }^{a}$ Department of Industrial and Mechanical Engineering, NTNU, Trondheim, Norway ${ }^{b}$ Advanced Material Simulation, S.L. Asturias 3. Bilbao 48015, Spain

\begin{tabular}{l}
\hline A R T I C L EI N F O \\
\hline Article history: \\
Received 6 July, 2016 \\
Accepted 3 November 2016 \\
Available online \\
6 November 2016 \\
\hline Keywords: \\
Notched plates \\
Mixed mode loading \\
Local strain energy density \\
Cohesive zone model
\end{tabular}

\section{Introduction}

In recent years, the mode I fracture of notched samples made of brittle or quasi-brittle materials has been studied by different authors (Carpinteri, 1987; Knésl, 1991; Nui et al., 1994; Seweryn, 1994; Gómez et al., 2000; Gomez \& Elices, 2003; Strandberg, 2002; Atzori \& Lazzarin, 2001; Gogotsi, 2003; Leguillon \& Yosibash, 2003; Yosibash, 2004; Dini \& Hills, 2004; Taylor, 2004; Lazzarin \& Zambardi, 2001; Lazzarin \& Berto, 2005). Under mixed mode (I+II) loading, the problem is more complex, even for brittle or quasi-brittle materials, and few failure criteria have been proposed for V-notches (Seweryn \& Lucaszewicz, 2002; Yosibash et al., 2006) giving more or less accurate predictions.

The first task of this paper is to provide a new set of experimental results on fracture of $U$ and $V$ notched samples, with different values of loading mixity, notch root radii and notch angles. The second * Corresponding author.

E-mail addresses: filippo.berto@ntnu.no (F. Berto) 
task is to investigate the possibility to use two fracture criteria in mixed mode fracture of notched components: the cohesive zone model and the strain energy density model, the latter applied to a finite size volume. After the description of the experimental program (all specimens made of PMMA and tested at $-60^{\circ} \mathrm{C}$ ), the paper presents the two different failure criteria as well as the numerical methods to use for fracture load assessments. The paper closes with a comparison between experimental data and expected values to failure.

\section{Experimental results}

Experiments were carried out by using specimens made of polymethyl-methacrylate (PMMA), a polymer that exhibits a non-linear behavior at room temperature and linear elastic up to fracture at $-60^{\circ} \mathrm{C}$ (Gomez et al., 2005). The average mechanical properties of PMMA at $-60^{\circ} \mathrm{C}$ appear in Table 1.

Table 1. Mechanical properties of PMMA at $-60^{\circ} \mathrm{C}$

\begin{tabular}{lll}
\hline Young's modulus & $\mathrm{E}=$ & $5.05 \pm 0.04 \mathrm{GPa}$ \\
Tensile strength & $\sigma_{\mathrm{u}}=$ & $128.4 \pm 0.1 \mathrm{MPa}$ \\
Fracture toughness & $\mathrm{K}_{\mathrm{IC}}=$ & $1.7 \pm 0.1 \mathrm{MPa} \mathrm{m}^{1 / 2}$ \\
Poisson's ratio & $\mathrm{v}=$ & $0.40 \pm 0.01$ \\
\hline
\end{tabular}

The experimental program considers $U$ and V-notched specimens, with different notch inclinations, notch opening angles, notch radii and boundary conditions. The geometry of the specimens is shown in Fig. 1. In all specimens the thickness was $14 \mathrm{~mm}$, the height $28 \mathrm{~mm}$, whereas the notch depth was $14 \mathrm{~mm}$. Four different geometries were tested, as indicated in Fig. 1 namely: standard U-notched beams, standard V-notched specimen, beams with a tilted U-notch and beams with tilted V-notch. In standard vertical U-notched beams, seven values of the notch root radius, $R$, were tested; $R=0.0,0.2,0.3,0.5$, $1.0,2.0$ and $4.0 \mathrm{~mm}$. The position of the loading point, $b$, was changed to obtain different mixed mode boundary conditions (i.e. $b=-3,3,9,18,27$ and $36 \mathrm{~mm}$ ). A notch tip radius of 0.0 and $0.2 \mathrm{~mm}$ was analyzed only in combination with the distances $b=9,18,27$ and $36 \mathrm{~mm}$; each configuration was repeated three times so that a total number of 114 tests were performed for this group of notches.

For standard V-notched beams, three values of the notch opening angle $\alpha$ were analyzed: $\alpha=30^{\circ}$, $60^{\circ}$ and $90^{\circ}$. Mixed mode loading was introduced by changing the loading position $b$ (Fig. 1). Two values were considered; $b=1$ and $9 \mathrm{~mm}$ and 18 different samples were tested. To increase the mode II contribution, geometries with 45 degrees inclined notch have been considered (Fig 1). Five notch root radii, $R=0.3,0.5,1.0,2.0$ and $4.0 \mathrm{~mm}$, and three support span, $m=3,9$ and $15 \mathrm{~mm}$, were explored resulting in 15 different geometries and a total number of 45 tests.

For tilted V-notched beams, three notch angles were studied; $\alpha=30^{\circ}, 60^{\circ}$ and $90^{\circ}$, and, two values of support span $m$ were considered, as shown in Fig. $1 ; \mathrm{m}=9$ and $18 \mathrm{~mm}$. 18 different samples were tested. Before testing, the radius and the angle of the notch were measured with an image analysis system. The tests were performed on a servo controlled INSTRON 8803 testing machine. The load was measured with a $5 / 10 \mathrm{kN}$ INSTRON load cell with $\pm 0.5 \%$ error at full scale. An MTS strain gauge extensometer, with $\pm 1 \mathrm{~mm}$ nominal displacement and $\pm 0.15 \%$ error at full scale was used for measuring the displacement of the point where the load was applied. The testing set-up was placed inside an INSTRON environmental chamber and cooled to $-60^{\circ} \mathrm{C}$. Cooling was achieved by pouring liquid nitrogen inside the chamber in a controlled and continuous flow. Temperature was measured using a K-type thermocouple placed on the sample surface, near the notch. Testing was done in three phases (Gomez et al. 2005); during the first the sample was cooled down to $-60^{\circ} \mathrm{C}$ in about 30 min and subjected to a small pre-load under load control. Then, the sample temperature was stabilized, still under load control, for 45 minutes. And finally, the sample was tested under displacement control at rate of $0.03 \mathrm{~mm} / \mathrm{min}$ at constant temperature. After each test the TPB experimental device has heated to avoid condensed water over it. All in all, 195 fracture tests were performed. 


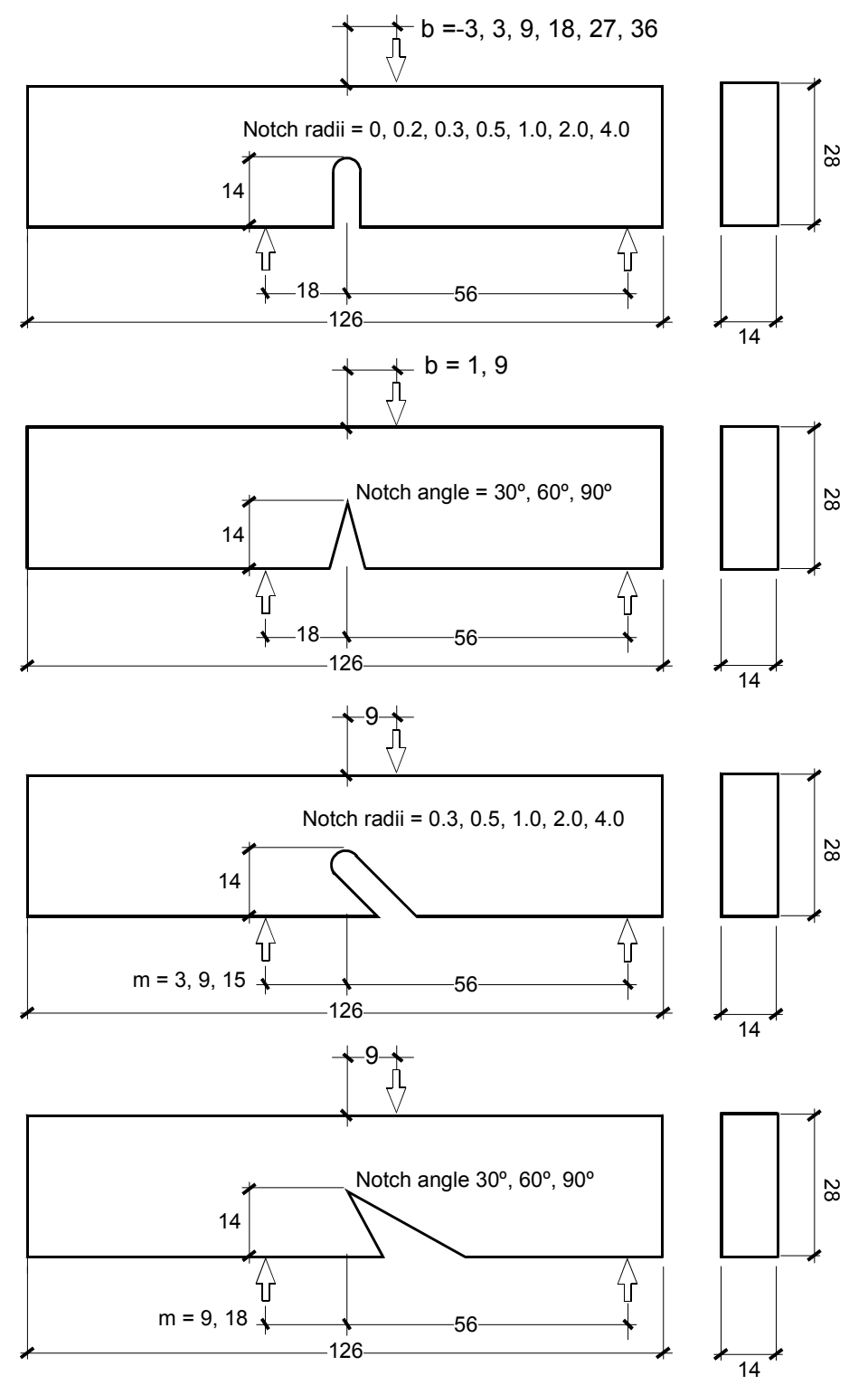

Fig. 1. Geometry and loading conditions. Data in mm

\section{Failure criteria}

\subsection{The averaged strain energy density criterion}

The averaged strain energy density criterion assumes that failure starts when the mean value of the strain energy density over a control volume is equal to a critical energy $\mathrm{W}_{\mathrm{c}}$ (Yosibash et al., 2004; Lazzarin \& Zambardi, 2001: Lazzarin \& Berto, 2005). The control volume section is a circle in the case of cracks or sharp V-notches and a crescent shape in U or blunts V-notches (Lazzarin \& Zambardi, 2001; Lazzarin \& Berto, 2005). In both cases the size is constant, equal to a material parameter, $\mathrm{R}_{\mathrm{c}}$. In order to apply the criterion two independent parameters are needed: the critical value of the strain energy, $\mathrm{W}_{\mathrm{c}}$, and the critical length, $\mathrm{R}_{\mathrm{c}}$. For a linear elastic material these two parameters could be obtained from the ultimate tensile stress $\mathrm{f}_{t}$ and the fracture toughness $\mathrm{K}_{\mathrm{IC}}$.

Under mixed mode loading it is assumed the equivalent local mode I approach, that establishes the critical volume is no centered on the notch tip, rather on the point where the principal stress reaches its 
maximum (Fig. 2). The crescent shape rotates rigidly, with no changes in shape and size (Gomez et al., 2007; Berto et al., 2007).
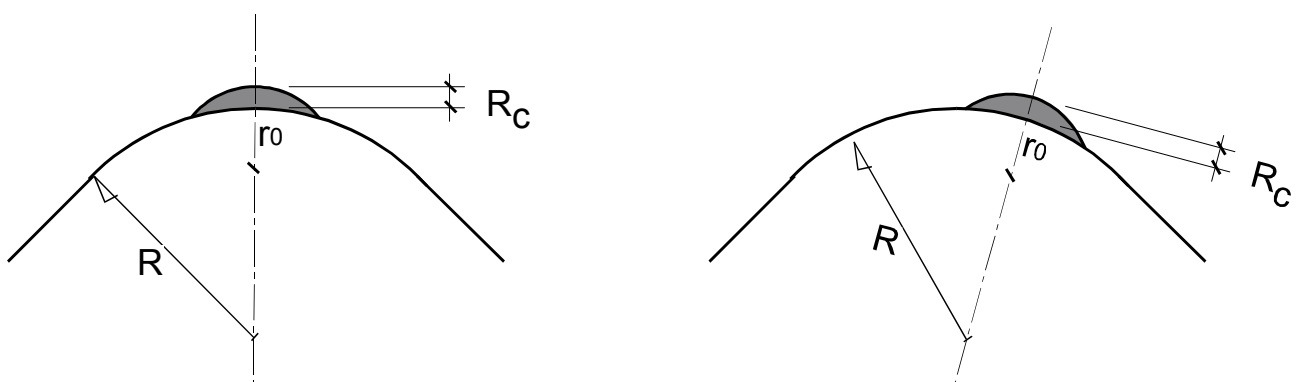

Fig. 2. Control volume under mixed mode loading

Following this criterion, the critical load is obtained when the mean strain energy density reaches the critical value $\mathrm{W}_{\mathrm{c}}$. The notched specimens have been numerically modelled using the finite element method with the commercial code ABAQUS v 6.3. Two calculations were performed for all geometries; the first one to determine the point of the notch edge where the principal stress reached its maximum vale; the second one to compute the averaged strain energy density on the control volume (Berto et al., 2007).

\subsection{The cohesive zone model criterion}

This model establishes two different regions: the cohesive crack zone and the bulk of the body (Bazant \& Planas, 1997; Elices et al., 2002). The behavior of the bulk material, PMMA at $-60^{\circ} \mathrm{C}$, can be approximated by an isotropic linear elastic material, and the behavior of the cohesive crack zone, simplified as a surface, is defined by the relationship between the stress transfer by the crack and the displacement of the lips, defined by the softening curve. In this research, the softening curve is assumed rectangular; this simple curve provides a reasonable estimation of the fracture behavior of PMMA at $60^{\circ} \mathrm{C}$ (Gomez et al. 2005). The rectangular softening curve depends only on two parameters: the cohesive stress $f_{t}$ and the fracture energy $G_{F}$. The cohesive stress $f_{t}$ is assumed equal to the tensile strength $\left(f_{t}=128 \mathrm{MPa}\right)$ and the fracture energy was obtain from the fracture toughness $(\mathrm{GF}=480 \mathrm{~N} / \mathrm{m}$. $)$. Under mixed mode loading the position of the cohesive crack zone is initially unknown. This problem could be overcome with the local mode I approach (Gómez et al., 2007), establishing that the cohesive cracks starts at the point where the principal stress reaches its maximum value and propagates initially perpendicular to the notch edge. This criterion predicts the mechanical behavior of the notch geometry. Calculations were performed with the freeware finite element code COFE, developed in the Department of Materials Science at the Universidad Politécnica de Madrid (Planas \& Sancho, 2007). Details of calculations could be found in (Berto et al., 2007).

\section{Results}

In order to check the applicability and the degree of accuracy of the strain energy density criterion (SED) and the cohesive zone model (CZM) when applied to fracture behavior assessments of PMMA specimens tested at $-60^{\circ} \mathrm{C}$ under mixed mode loading, the numerical and the experimental values of the maximum load to failure were compared. Fig. 3 compares, for vertical standard U-notched beams, the experimental values of the critical load, with the numerical predictions based on the CZM model and the SED model. There are six figures corresponding to six different mixed load conditions, $b=-3,3$, $9,18,27,36 \mathrm{~mm}$. As can be seen, the two models fit with a good accuracy all experimental results. 

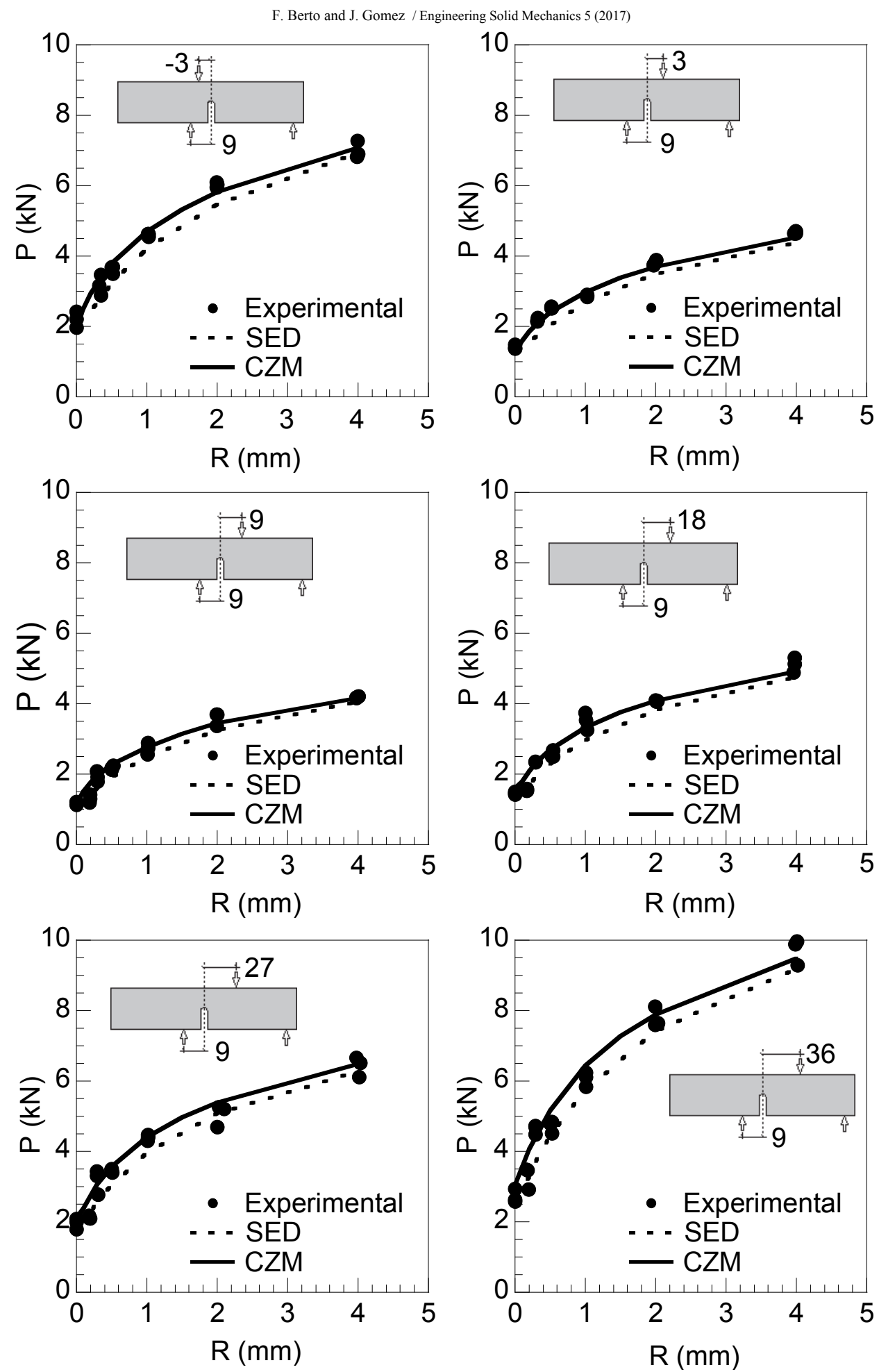

Fig. 3. Experimental and predicted values of the maximum load in standard U-notches

Fig. 4 compares for tilted U-notched beams, the critical loads experimental and numerical. The three figures correspond to three different mixity loading as obtained changing the support span; $m=$ 15, 9, $3 \mathrm{~mm}$. The same comments, as for Fig. 3, can be drawn. 

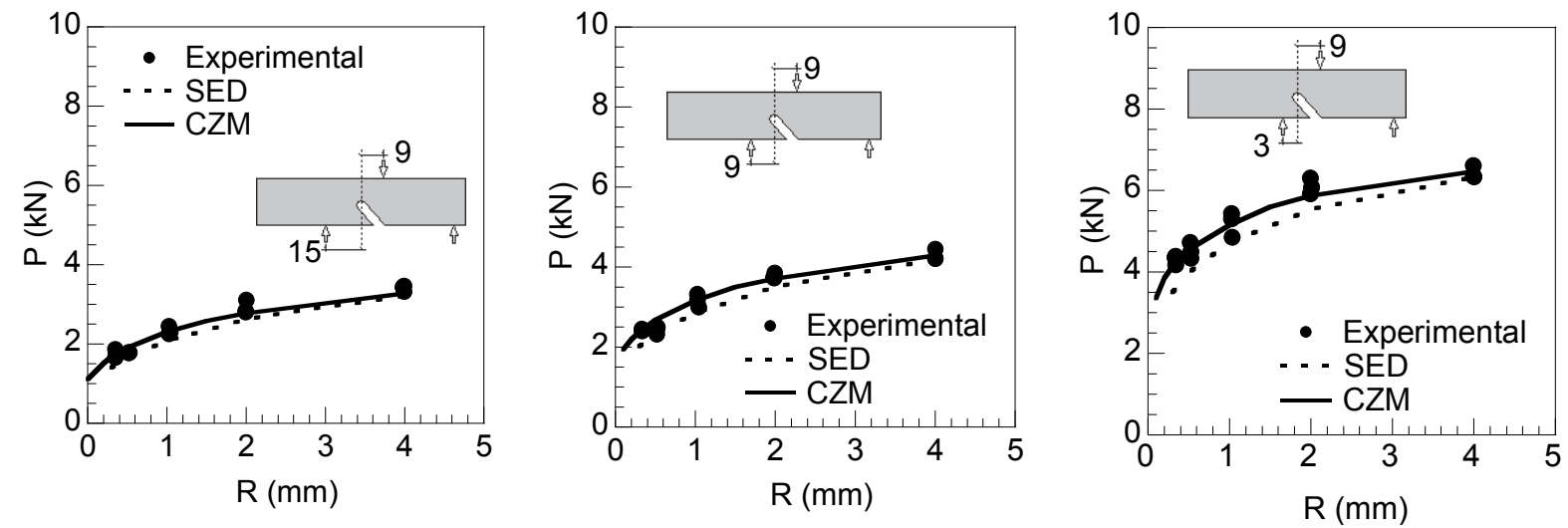

Fig. 4. Experimental and predicted values of the maximum load in tilted U-notches

Dealing with V-notches two limit values of the radius at the tip were introduced in the model; 0 and $0.1 \mathrm{~mm}$. Fig. 5 compares the critical experimental loads and the numerical values for V-notched beams, the upper line corresponding to a radius of $0.1 \mathrm{~mm}$ and the lower one to a radius of $0 \mathrm{~mm}$. As can be seen again, the two models fit all experimental results.
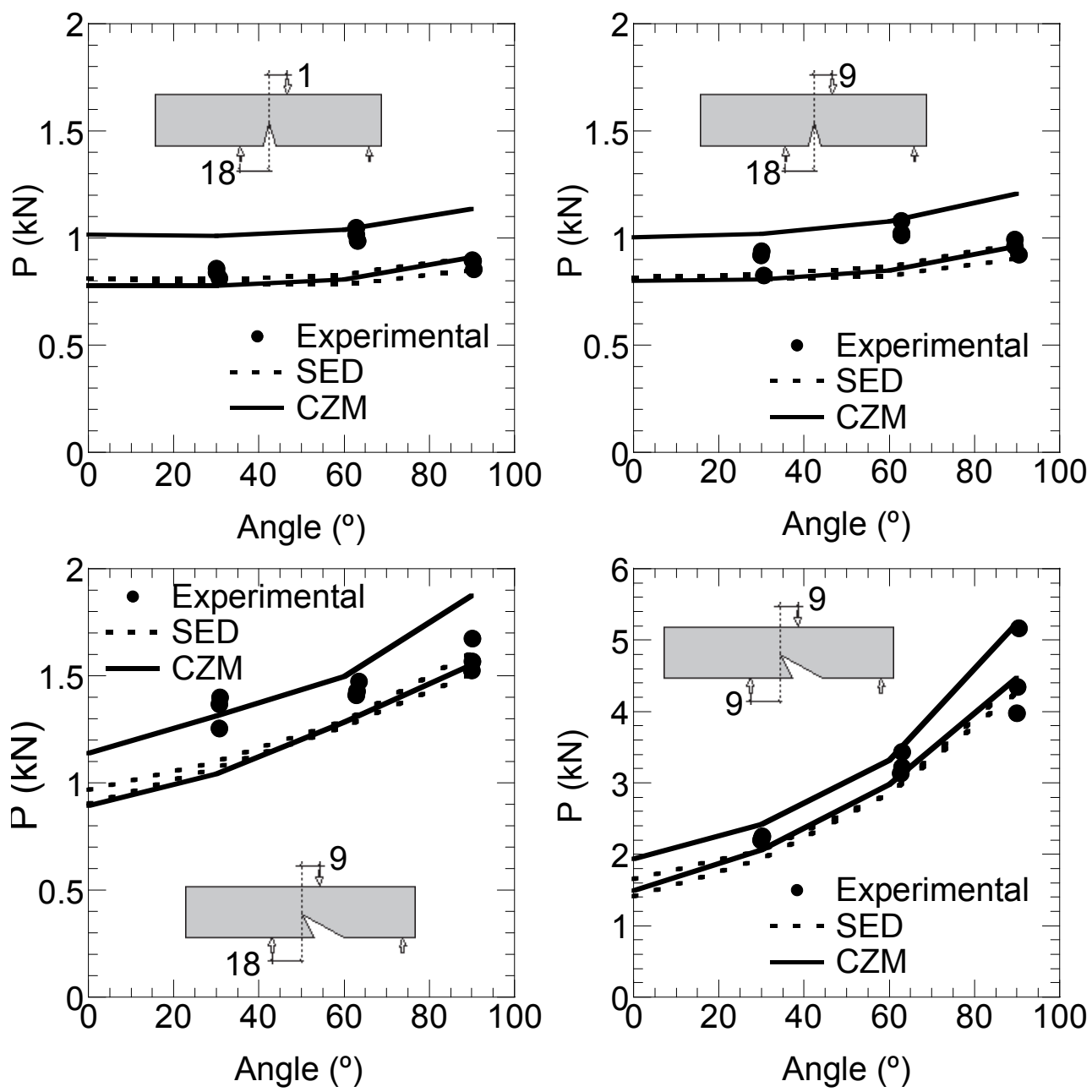

Fig. 5. Experimental and predicted values of the maximum load in V-notches 


\section{Conclusions}

This research provides the results of a huge experimental program of fracture tests carried out on notched specimens under mixed mode (I+II) loading. A total number of 195 fracture tests has been performed by using a linear elastic material, PMMA at $-60^{\circ} \mathrm{C}$. Different notches, $\mathrm{U}$ and $\mathrm{V}$, notch opening angles, notch root radii and loading conditions have been analyzed.

Two models are proposed: the cohesive zone model (CZM) and the strain energy density (SED) over a control volume. Both methods are able to predict the maximum load that a notched specimen can support under mixed mode. The agreement between the numerical predictions and the experimental results is good. This fact confirms the applicability of the two procedures to mixed mode loading conditions, the accuracy being comparable to that already shown under mode $\mathrm{I}$, as documented in previous analyses carried out by the same authors.

\section{References}

Atzori, B., \& Lazzarin, P. (2001). Notch sensitivity and defect sensitivity under fatigue loading: two sides of the same medal. International Journal of Fracture, 107(1), 1-8.

Bazant, Z. P., \& Planas, J. (1997). Fracture and size effect in concrete and other quasibrittle materials (Vol. 16). CRC press.

Berto, F., Lazzarin, P., Gómez, F. J., \& Elices, M. (2007). Fracture assessment of U-notches under mixed mode loading: two procedures based on the 'equivalent local mode I'concept. International Journal of Fracture, 148(4), 415-433.

Carpinteri, A. (1987). Stress-singularity and generalized fracture toughness at the vertex of re-entrant corners. Engineering Fracture Mechanics, 26(1), 143-155.

Dini, D., \& Hills, D. A. (2004). Asymptotic characterisation of nearly-sharp notch root stress fields. International Journal of Fracture, 130(3), 651-666.

Elices, M., Guinea, G. V., Gomez, J., \& Planas, J. (2002). The cohesive zone model: advantages, limitations and challenges. Engineering Fracture Mechanics, 69(2), 137-163.

Gogotsi, G. A. (2003). Fracture toughness of ceramics and ceramic composites. Ceramics International, 29(7), 777-784.

Gómez, F. J., \& Elices, M. (2003). Fracture of components with V-shaped notches. Engineering Fracture Mechanics, 70(14), 1913-1927.

Gómez, F. J., Elices, M., \& Valiente, A. (2000). Cracking in PMMA containing U-shaped notches. Fatigue \& Fracture of Engineering Materials \& Structures, 23(9), 795-803.

Gómez, F. J., Elices, M., \& Planas, J. (2005). The cohesive crack concept: application to PMMA at60 C. Engineering Fracture Mechanics, 72(8), 1268-1285.

Gómez, F. J., Elices, M., Berto, F., \& Lazzarin, P. (2007). Local strain energy to assess the static failure of U-notches in plates under mixed mode loading. International Journal of Fracture, 145(1), 29-45.

Knésl, Z. (1991). A criterion of V-notch stability. International Journal of Fracture, 48(4), R79-R83.

Lazzarin, P., \& Zambardi, R. (2001). A finite-volume-energy based approach to predict the static and fatigue behavior of components with sharp V-shaped notches. International journal of fracture, 112(3), 275-298.

Lazzarin, P., \& Berto, F. (2005). Some expressions for the strain energy in a finite volume surrounding the root of blunt V-notches. International Journal of Fracture, 135(1-4), 161-185.

Leguillon, D., \& Yosibash, Z. (2003). Crack onset at a v-notch. Influence of the notch tip radius. International Journal of Fracture, 122(1-2), 1-21.

Nui, L. S., Chehimi, C., \& Pluvinage, G. (1994). Stress field near a large blunted tip V-notch and application of the concept of the critical notch stress intensity factor (NSIF) to the fracture toughness of very brittle materials. Engineering Fracture Mechanics, 49(3), 325-335.

Planas, J., \& Sancho, J. M. (2007). Computational orientated finite elements. COFE. Internal report. JP0501. Departamento de Ciencia de los Materiales. Universidad Politécnica de Madrid.

Seweryn, A. (1994). Brittle fracture criterion for structures with sharp notches. Engineering Fracture Mechanics, 47(5), 673-681. 
Seweryn, A., \& Łukaszewicz, A. (2002). Verification of brittle fracture criteria for elements with Vshaped notches. Engineering Fracture Mechanics, 69(13), 1487-1510.

Strandberg, M. (2002). Fracture at V-notches with contained plasticity. Engineering Fracture Mechanics, 69(3), 403-415.

Taylor, D. (2004). Predicting the fracture strength of ceramic materials using the theory of critical distances. Engineering Fracture Mechanics, 71(16), 2407-2416.

Yosibash, Z., Bussiba, A., \& Gilad, I. (2004). Failure criteria for brittle elastic materials. International Journal of Fracture, 125(3-4), 307-333.

Yosibash, Z., Priel, E., \& Leguillon, D. (2006). A failure criterion for brittle elastic materials under mixed-mode loading. International Journal of Fracture, 141(1-2), 291-312.

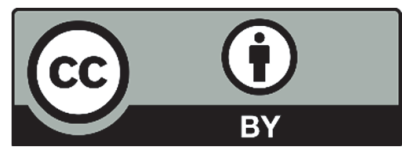

(C) 2017 by the authors; licensee Growing Science, Canada. This is an open access article distributed under the terms and conditions of the Creative Commons Attribution (CC-BY) license (http://creativecommons.org/licenses/by/4.0/). 